\title{
A Mathematical Modeling Approach for Materials Requirements Planning in Remanufacturing
}

\author{
Rızvan Erol $^{\mathrm{a}} \quad$ Gülsün Nakıboğlu ${ }^{\mathrm{b}}$
}

\begin{abstract}
Remanufacturing has become an ever more important topic due to a growing need for environmentalfriendly production strategies and an efficient use of resources. Traditional materials requirements planning (MRP) methods need to be adjusted in line with these new manufacturing environments where both manufacturing and remanufacturing are involved. In this study, a mathematical programming model is formulated for materials requirements planning decision in a multi-product, multi-period remanufacturing system where the assembly of final product is done both through use of parts procured from the disassembly of returned (used) (core) products and by ordering new (unused) parts. The decisions regarding the purchase and disassembly of new parts or used products as part of materials requirements planning are made for the purpose of minimizing the costs. The developed model takes into account, in a deterministic manner, the quality of the product to be disassembled, disposal cost of defective cores, lead time for purchasing new parts, disassembly bill of materials, disassembly capacity and disassembly time of each part. The mathematical model is illustrated through application to a sample problem, and an experimental design is provided in order to identify the ways in which different conditions in a manufacturing environment affect the total cost of the system.
\end{abstract}

Keywords: Remanufacturing, Materials Requirements Planning (MRP), Reverse Logistics, Disassembly, Mathematical Modeling

JEL Classification: C61, M190, Q53

\section{Introduction}

Topics such as the benefits of green production, social responsibility, legislative regulations, environmentally conscious manufacturing, reverse logistics and product recovery have recently gained growing attention due to increased environmental concerns of consumers (Inderfurth, 2004; Rubio and Corominas, 2008; Li, Gonzalz and Zhu, 2009; Nenes and Nikolaidis, 2012). The collection and reuse of products and materials have a long history and hence are not new concepts as seen in the long-standing practices of paper recycling, scrap metal collecting and deposit systems for glass bottles. However, all these operations need to be systematically performed and managed in order to benefit from reverse logistics.

Product recovery aims to minimize the amount of waste through recovering parts and materials from returned products by means of recovery options such as remanufacturing or recycling (Nakashima, Arimitsu, Nose and Kuriyama, 2002). Reverse logistics represents the first stage of product recovery from the point of

aProf. Dr., Çukurova University, Faculty of Engineering and Architecture, Department of Industrial Engineering, Adana, Turkiye, rerol@cukurova.edu.tr

${ }^{b}$ Assist. Prof., Çukurova University, Faculty of Engineering and Architecture, Department of Business Administration, Adana, Turkiye, ngulsun@cukurova.edu.tr 
view of the supply chain. There are numerous definitions of reverse logistics suggested in the literature (e.g. Fleischmann et al., 1997; Dowlatshahi, 2000; Brito and Dekker, 2002; Rogers and Tibben-Lembke, 2001; Stock, 2001; Kim, Song, Kim and Jeong, 2006). As a notable example among others, Carter and Ellram (1998) describe reverse logistics as a process through which firms can become more environmentally efficient by means of recycling, reusing and reducing the amount of materials used.

Figure 1 shows the basic product recovery options in reverse logistics. All of these options require the product to be collected, processed and redistributed into the market (Guide and Jayaraman, 2000). The key difference between them lies in the processes of reprocessing and recovery. Remanufacturing, which is one of the recovery options shown in Figure 1 and constitutes the main subject of this paper, refers to the process of recovering materials from used products (Tang, Grubbstrom and Zanoni, 2004). In other words, it is the process through which used products are restored to meet quality standards set for new products. Accordingly, old or worn-out products are completely disassembled in the process of remanufacturing, and their components are removed, cleaned and inspected if necessary, while some parts can also be replaced and upgraded as needed. Subsequently, the product is reassembled and tested to verify if it meets the performance level of a new product. Therefore, it is possible to upgrade an old or worn-out product in this process of remanufacturing. A remanufactured product can thus be composed of both newly manufactured parts and disassembled components (Ijomah, Mcmahon, Hammond and Newman, 2007).

Figure 1. Product Recovery Options

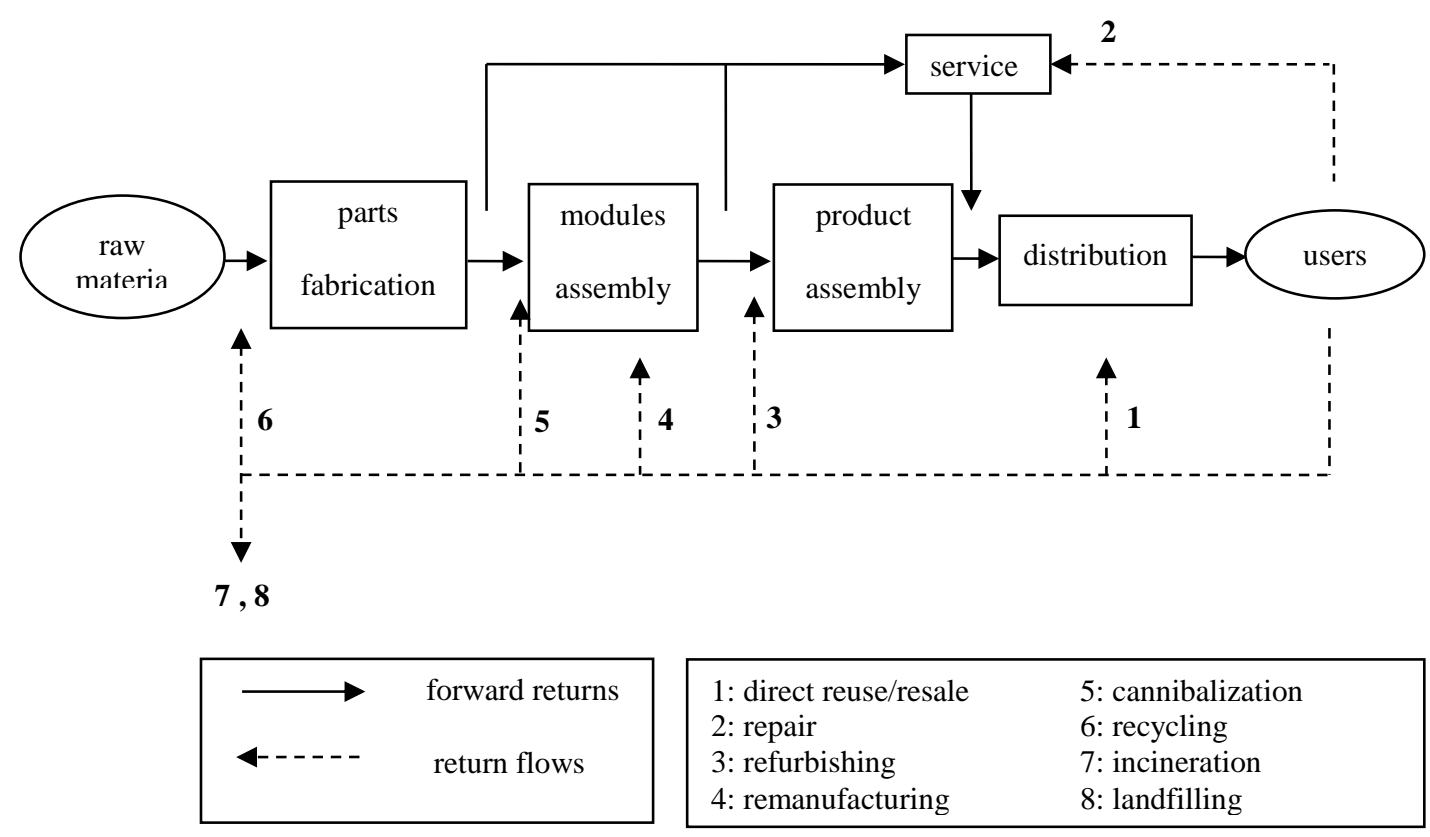

Source: Thierry, Salomon, Nunen and Wassenhove, 1995: 118.

Recoverable manufacturing systems, among which remanufacturing is included, have particular characteristics that create difficulties in management, planning and control of supply chain functions. This, in turn, further complicates materials planning by causing uncertainties in timing, quantity and quality of cores, part matching restrictions, stochastic routings and highly variable processing times (Guide, 1999; Gungor and Gupta, 1999; Guide, 2000; Guide, Jayaraman, Srivastava and Benton, 2000; Ferrer and Whybark, 2001; van Nunen and Zuidwijk, 2004). These characteristics hence prevent traditional production planning methods from being directly used in remanufacturing environments. For instance, information on the supply of different parts disassembled from different cores (or returned products) should be incorporated into materials planning decisions (Guide and Spencer, 1997). Furthermore, the capacity for disassembling cores needs to be checked for a feasible materials plan (Guide, Srivastava and Spencer, 1997). The majority of 
studies in the literature suggest that a new line named parts from disassembly is added into materials plan table.

There are few studies that have investigated materials planning decisions in remanufacturing environments. Most studies focus on disassembly planning which involves determining the quantity of used products to be ordered in order to fulfill the need for parts and subassemblies obtained from disassembly. Some of these studies alternatively refer to disassembly scheduling as reversed materials requirement planning (RMRP) since the problem in question is basically a reversed form of the regular MRP (see Lee, Kang and Xirouchakis, 2001; Inderfurth and Langella, 2006; Barba-Gutierrez, Adenso-Diaz and Gupta, 2008). In another example of the works related to MRP, Gupta and Taleb (1994) present a materials requirements planning for a simple product structure where parts disassembled from cores are the only source to be used as parts for new items. Veerakamolmal and Gupta (2000) study a materials planning problem with deterministic core numbers. In their formulation, part requirements are initially met from disassembled parts and new parts are only purchased if needed. The present study enables the decision maker to choose between these two options - disassembly versus purchase of new parts to manufacture new units - to maximize cost effectiveness. In another paper related to this study, Langella (2007) treats both disassembly and purchase of new parts to minimize the total cost of remanufacturing, thereby making an improvement to an earlier heuristic algorithm (Taleb and Gupta, 1997). However, unlike this study, he assumes individual core disassembly times (independent of the number of parts in the core) and zero lead times for cores and new parts.

In making such decisions on the sourcing of parts, any existing commonality in products and cores adds complexities that cannot be resolved through standard MRP computations. Most studies in the literature simply take into account a single product and/or single-period planning. Additionally, disassembled and recovered parts are used exactly in the same position in the products with no commonality. In the majority of works, there is also no overall optimization of disassembly and new part procurement decisions in a single optimization model. Generally speaking, these studies illustrate the steps that should be taken to make modifications on standard MRP tables such as adding new lines and computations if and when needed.

Remanufacturing systems produce multiple products with commonality in bill of materials. Parts needed for manufacturing can be obtained through purchase of new parts or disassembled cores. Figure 2 illustrates physical flows of materials through the remanufacturing system studied.

Figure 2. Remanufacturing System

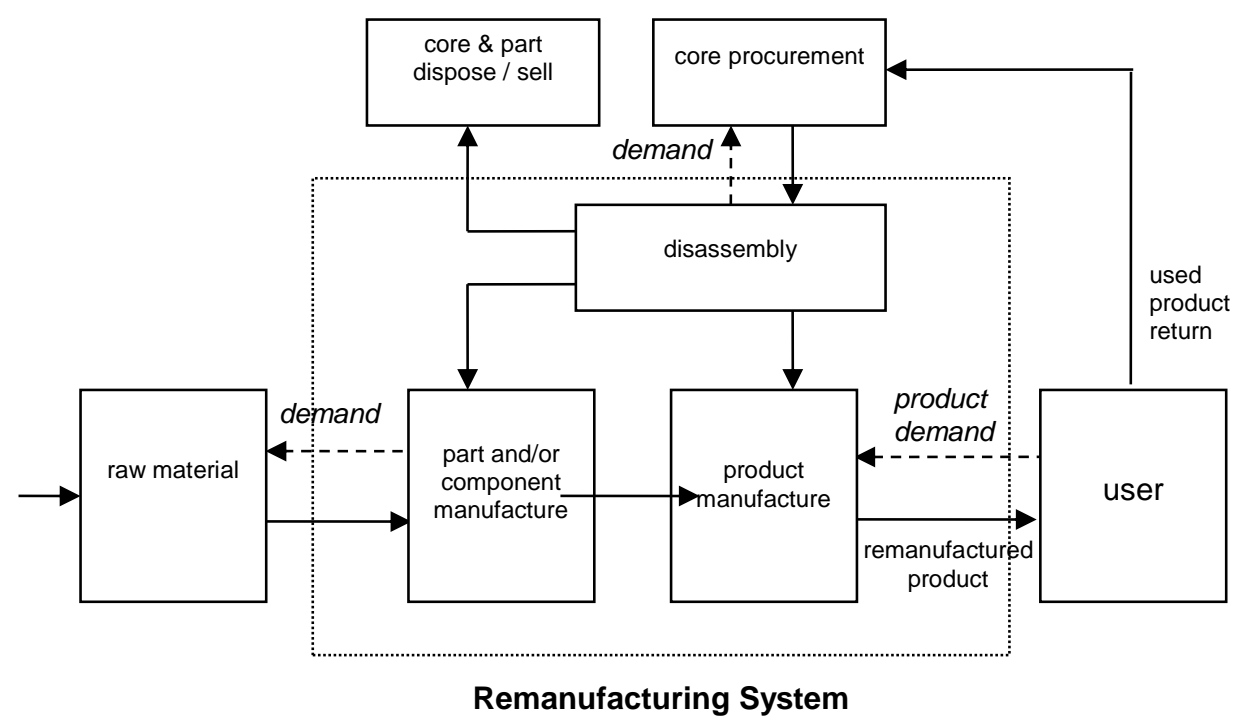

Source: Adapted from Guide, Jayaraman and Srivastava, 1999: 222. 
This study focuses on tactical and operational decisions for materials requirements planning in remanufacturing environments. It is necessary to take into account uncertainties in timing, quantity and quality of cores in materials planning to avert interruptions in manufacturing. At the stage of disassembly, separation time and disassembly yield rates are other important factors in the formulation of the problem. The parts and components that are needed in assembling the final product are sourced through purchase of new parts or acquirement and disassembly of cores. Parts that are obtained through disassembly of the cores but not needed for the manufacturing are not discarded but instead stored in addition to the needed parts, which in turn increases the holding costs. At this point, the main decision is to determine which core should be disassembled for which part in view of the capacity constraints and total cost of running the system. This study proposes a mathematical programming model through which to optimally make such decisions. The problem formulation for the mathematical model is elaborated in the following sections.

Manufacturers can obtain cores through retailers, warehouses or third-party providers, and they can return cores directly without any agent. Guide (2000) points out that most firms (81.8\%) acquire cores directly from the customer whereas only some firms resort to core brokers (9.2\%) or third-part agencies (7.3\%). The present study, however, does not make any distinction between core suppliers.

Remanufacturing environments have more types of inventory than traditional manufacturing systems do. Among these are included (1) product inventory, (2) core inventory, (3) inventory of purchased new (unused) parts, and (4) parts which are disassembled from cores. At this point, materials requirements planning can be expected to answer how to source a needed part. As Taleb and Gupta (1997) point out, there is only a single demand source in traditional assembly whereas, in a disassembly environment, each part also constitutes a source of demand. Therefore, fulfilling the demand for those separate parts cannot be done in an independent manner since some of these parts share the same procurement source(s).

Another difficulty involved in remanufacturing is the inability to know the exact quantity of returned cores. As noted in Guide (2000), the $61.5 \%$ of firms reported that they had no control over the timing or quantity of returns. In the present model, the quantity of cores which can be disassembled is determined by the model for each period. Ferrer and Whybark (2001) assume core quantity as having an uncertain rate of sales. In this formulation, the user can define a maximum availability level for the supply of a core from different sources. Additionally, a minimum number of cores needs to be disassembled each period due to the legal requirements or social responsibilities. Furthermore, disassembly is performed in the presence of a capacity constraint. Although remanufacturing saves the cost of components and parts, remanufacturing and disassembly operations in particular are inherently more labor intensive (Ferrer and Ayres, 2000; Grubbstrom and Tang, 2006). Therefore, the capacity constraint should be taken into consideration in the model. After the quality inspection process, defective cores are disposed with a unit disposal cost. This situation is shown in the model as defective rate.

Unlike certain works in the literature on partial disassembly, this study assumes the complete disassembling of cores. Further, this study assumes that core disassembly cost and time of a part vary depending on the core type, unlike other studies which use a fixed core disassembly cost and time for all parts. The parts and quantities which can be obtained from disassembly are indicated in a disassembly bill of materials (DBOM). Theoretical quantities shown in DBOM may not be achieved at all times because of the likelihood of disruption or fracture during the disassembly of parts made of low-quality materials. According to Mukhopadhyay and Ma (2009), the amount of the parts which can be recovered is uncertain in many cases because returned products are not pre-sorted and information about their quality is largely limited. Therefore, in addition to the quality condition of the cores, it is also necessary to take yield rate of disassembly into account in calculating the usable parts in manufacturing. Guide and Jayaraman (2000) argue that material recovery rate may change between $20 \%$ and $82 \%$.

The holding costs of core, new part, disassembled part and product are deterministic. Guide and Jayaraman (2000) indicate that $40 \%$ of firms report using a fixed holding cost with values ranging from $5 \%$ to $20 \%$ of the purchase price of the core. 
Another important characteristic of recovery operations is commonality. Commonality can be defined as using the same part as a component in more than one product and/or multiple times in a single product. Commonality is often preferred in manufacturing because of its benefits such as lower (part) purchasing and inventory costs (Taleb and Gupta, 1997). However, commonality hampers the scheduling of disassembly since it creates dependencies between the components of the product structure (Taleb, Gupta and Brennan, 1997). This commonality may be within a product, or, in the case of multi-product environments, the part commonality may be across products (commonality). Although both commonalities provide firms with several advantages such as economies of scale in purchasing, learning curve effect, they also complicate planning the disassembly and calculating the optimal number of cores needed to fulfill demand for parts (Langella, 2007). The same part can be disassembled from different cores with different costs. In this study, commonality across the products is considered as it is more common in practice.

The existing literature largely calculates the needs for disassembled parts rather than for core products. In this study, the demand for remanufactured products and the disassembly bill of materials are both considered for multi-periods. In addition to disassembled parts, another contribution of this study lies in introducing a new parts purchasing decision which should be considered on the basis of costs. In comparison with the previous studies, our study has broader considerations in terms of the number of planning periods, core, parts and final products. Another contribution is the inventories of new and disassembled parts the costs of which are also separately taken. Furthermore, this study also considers the core quality level, disassembly yield rate, lead times for new parts and cores, core disposal and part commonality, which renders our decision model more realistic.

\section{Mathematical Model}

Our model makes a decision about disassembly of cores or purchase of new parts to fulfill the demand at a minimum cost. The main purpose of the mathematical model is to meet the demands in each planning period through minimizing the costs of acquiring cores, purchasing new parts, disposing cores and the holding cost for new parts, disassembled parts and final products, while performing the manufacturing of products at the same time. The model have constraints related to the available number of total cores from suppliers, capacity constraints for disassembly, minimum number of disassembly of cores (eg. legal requirements or social responsibilities). In our model, disassembly cost and time depend on the part which is in the core product. Disassembly yield rates (quality problems) are also taken into account and the core disposal is further added to the model in case the core does not meet the quality level required/desired. The notation for the mathematical model is as follows:

Indices

$\begin{array}{lll}t & \text { time periods } & (t=1, \ldots, \mathrm{T}) \\ i & \text { products } & (j=1, \ldots, \mathrm{I}) \\ j & \text { parts } & (j=1, \ldots, \mathrm{J}) \\ k & \text { cores } & (k=1, \ldots, \mathrm{K}) \\ l & \text { core suppliers } & (l=1, \ldots, \mathrm{L})\end{array}$

\section{Decision Variables}
$P P_{j t} \quad$ number of purchased new part $j$ at period $t$
$C P_{k t} \quad$ number of purchased core $k$ at period $t$
$Z_{k t} \quad$ number of disassembled core $k$ at period $t$
$D P_{j t} \quad$ number of part $j$ obtained from disassembly at period $t$
$I_{i t} \quad$ inventory of product $i$ at end of period $t$ 

$I N_{j t} \quad$ inventory of new part $j$ at end of period $t$
$I D_{j t} \quad$ inventory of disassembled part $j$ at end of period $t$
$I C_{k t} \quad$ inventory of core $k$ at end of period $t$
$U_{i t} \quad$ number of manufactured product $i$ at period $t$
$U N_{j t} \quad$ number of new part $j$ used in manufacturing at period $t$
$U D_{j t} \quad$ number of disassembled part $j$ used in manufacturing at period $t$
$\delta_{j t} \quad$ binary variable to indicate whether to order any new part $j$ at period $t$
$\theta_{k t} \quad$ binary variable to indicate whether to order any core $k$ at period $t$

\section{Performance measures}

TC total cost over the planning period $T$

\section{Parameters}

$D U_{i t} \quad$ demand for product $i$ at period $t$

$D_{j t} \quad$ requirement for part $j$ at period $t$

$C C_{k l} \quad$ unit purchasing cost from supplier / for core $k$

$C D_{k j} \quad$ disassembly cost of part $j$ from core $k$

$C B_{j} \quad$ unit purchasing cost of a new part $j$

$H U_{i} \quad$ unit holding cost of product $i(\$ /$ unit/period)

$H N_{j} \quad$ unit holding cost of new part $j(\$ /$ unit/period)

$H D_{j} \quad$ unit holding cost of disassembled part $j$ (\$/unit/period)

$H C_{k} \quad$ unit holding cost of core $k$ (\$/unit/period)

$Q_{k t l} \quad$ maximum available core quantity from supplier $/$ at period $t$

$N_{k t} \quad$ minimum quantity of core $k$ which must be disassembled at period $t$

$C X_{k} \quad$ unit disposal cost of core $k$

$Y_{k} \quad$ disassembly yield rate of core $k$

$\alpha_{k} \quad$ defective percentage of core $k$

$v \quad$ lead time for a core

$w \quad$ lead time for a new part

$B O M_{i j}$ number of part $j$ in BOM of product $i$

$D B O M_{k j}$ number of part $j$ in DBOM of core $k$

$D T_{k j} \quad$ disassembly time of part $j$ from core $k$

$D L C_{t} \quad$ available disassembly capacity at period $t$ (time unit/period)

$\mathrm{COU}_{j t}$ ordering cost for new part $j$ (\$/order)

$\mathrm{COC}_{k t}$ ordering cost for core $k$ (\$/order) 
The objective function seeks to minimize the total production cost over a fixed planning horizon $(T)$. The following cost factors are considered in the objective function: (i) purchasing cost of core, (ii) purchasing cost of new part, (iii) core disassembly cost, (iv) product holding cost, (v) new part holding cost, (vi) holding cost of disassembled part, (vii) core holding cost, (viii) core disposal cost, (ix) ordering cost of new part and $(x)$ ordering cost of core.

The overall mathematical programming model is as follows:

$$
\begin{gathered}
\operatorname{Min} \mathrm{TC}=\sum_{t=1}^{T}\left[\sum_{l=1}^{L} \sum_{k=1}^{K} C C_{k l} \times C P_{k t}+\sum_{j=1}^{J} C B_{j} \times P P_{j t}+\sum_{k=1}^{K} \sum_{j=1}^{J} C D_{k j} \times Z_{k t}+\sum_{i=1}^{I} H U_{i} \times I U_{i t}\right. \\
+\sum_{j=1}^{J} H N_{j} \times I N_{j t}+\sum_{j=1}^{J} H D_{j} \times I D_{j t}+\sum_{k=1}^{K} H C_{k} \times I C_{k t}+\sum_{k=1}^{K} C X_{k} \times\left(C P_{k t} \times \alpha_{k}\right) \\
\left.+\sum_{j=1}^{J} \delta_{j t} \times C O U_{j t}+\sum_{k=1}^{K} \theta_{k t} \times C O C_{k t}\right]
\end{gathered}
$$

$$
\begin{aligned}
& I U_{i t}=I U_{i, t-1}+U_{i t}-D U_{i t} \quad \forall i, t \\
& I N_{j t}=I N_{j, t-1}+P P_{j, t-w}-U N_{j t} \quad \forall j, t \\
& I D_{j t}=I D_{j, t-1}+D P_{j, t}-U D_{j t} \quad \forall j, t \\
& I C_{k t}=I C_{k, t-1}+\left(1-\alpha_{k}\right) C P_{k, t-v}-Z_{k t} \quad \forall k, t \\
& D P_{j t}=\sum_{k=1}^{K} Z_{k t} \times D B O M_{k j} \times Y_{k} \quad \forall j, t \\
& \begin{array}{ll}
D_{j t}=\sum_{i=1}^{I} U_{i t} \times B O M_{i j} & \forall j, t
\end{array} \\
& D_{j t}=U D_{j t}+U N_{j t} \quad \forall j, t \\
& C P_{k t} \leq \sum_{l=1}^{L} Q_{k t l} \quad \forall k, t \\
& I C_{k t} \geq Z_{k t} \quad \forall k, t \\
& \sum_{k=1}^{K} \sum_{j=1}^{J} D T_{k j} \times Z_{k t} \leq D L C_{t} \quad \forall t \\
& Z_{k t} \geq N_{k t} \quad \forall k, t \\
& P P_{j t} \leq M \times \delta_{j t} \quad \forall j, t \\
& C P_{k t} \leq M \times \theta_{k t} \quad \forall k, t \\
& \delta_{j t}=\left\{\begin{array}{ll}
1, & \text { if } P P_{j t}>0 \\
0, & \text { otherwise }
\end{array} \forall j, t\right. \\
& \theta_{k t}=\left\{\begin{array}{ll}
1, & \text { if } C P_{k t}>0 \\
0, & \text { otherwise }
\end{array} \quad \forall k, t\right.
\end{aligned}
$$




\section{$M$ :big number}

$$
\begin{array}{cc}
Z_{k t}, P P_{j t}, I U_{i t}, I N_{j t}, I D_{j t}, I C_{k t}, U_{i t}, U N_{j t}, D P_{j t}, U D_{j t}, C P_{k t}, D_{j t} \geq 0 & \forall i, j, k, t \\
\delta_{j t}, \theta_{k t} \in(0,1) & \forall j, k, t
\end{array}
$$

Equations (1), (2), (3) and (4) are inventory balance equations for product, new parts, disassembled parts and cores, respectively. The number of parts obtained from disassembling a core is indicated in equation (5). Equation (6) calculates part requirements from production bill of materials. Equation (7) ensures that demand for each part is satisfied at each period. On the one hand, constraint (8) limits the number of available cores by the total core capacities of the suppliers. On the other hand, constraint (9) limits the number of cores that can be disassembled by core inventory level at that period. Core disassembly capacity and minimum core disassembly constraints are given in (10) and (11), respectively. Constraints (12) and (13) ensure that ordering costs for new parts and cores are accounted in the total cost in the case of any purchase of new parts and cores at any period, respectively. Binary variables corresponding to ordering costs are defined in equations (14) and (15).

\section{A numerical Example}

This section presents a numerical example to illustrate how to use the mathematical programming model developed in the present study. The example in question has 3 final products, 5 part types and two different cores. The planning horizon is assumed to be 5 periods. Figure 3 shows the BOMs for the final products while Figure 4 indicates the DBOMs for the cores. These DBOMs have no intermediate levels for parts since only requirements for parts at the lowest level need to be computed. In most remanufacturing systems, the disassembly of the cores is performed down to parts at the lowest level of DBOM. Even if a core may have multiple levels of parts, disassembly costs, disassembly times and obtained part quantities all depend on the lowest level parts.

Figure 3. BOMs for the Final Products in the Illustrative Example Problem

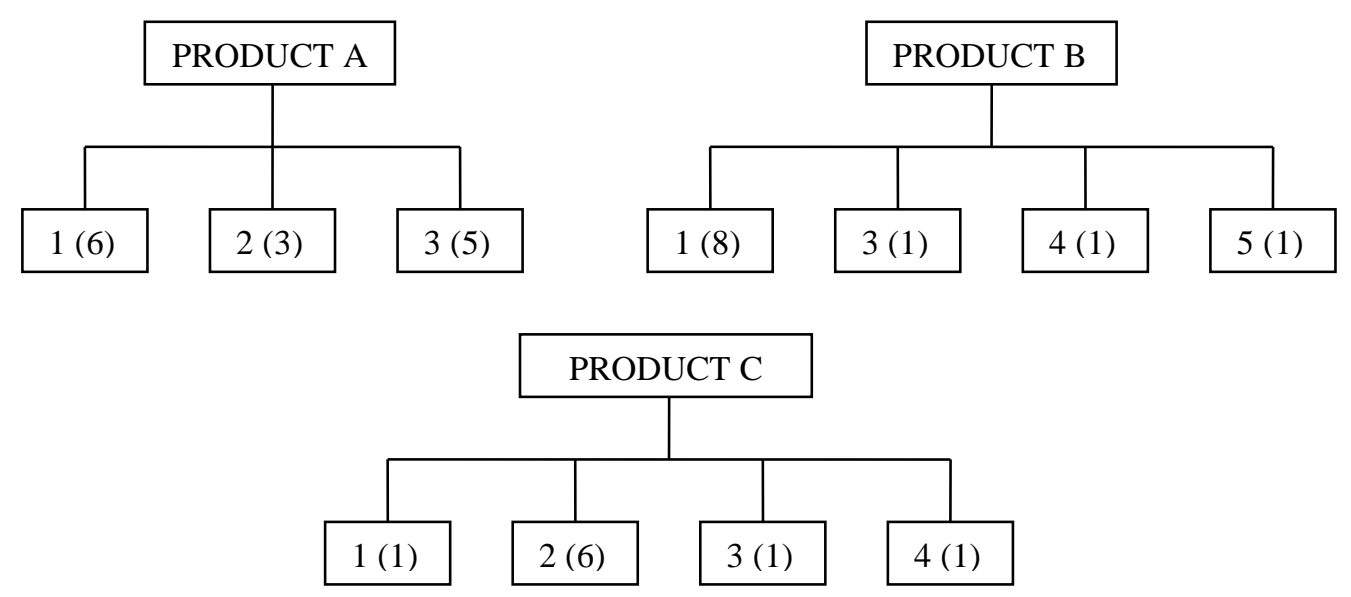


Figure 4. DBOMs for the Cores in the Illustrative Example Problem
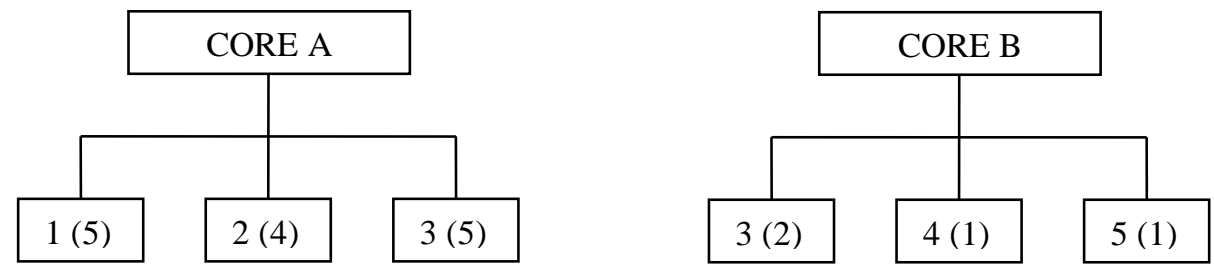

BOMs and DBOMs may be expressed in a matrix form as in the following for the ease of computer programming.

$$
\mathrm{BOM}=\left[\begin{array}{lllll}
6 & 3 & 5 & 0 & 0 \\
8 & 0 & 1 & 1 & 1 \\
1 & 6 & 1 & 1 & 0
\end{array}\right] \quad \text { DBOM }=\left[\begin{array}{lllll}
5 & 4 & 5 & 0 & 0 \\
0 & 0 & 2 & 1 & 1
\end{array}\right]
$$

Demand and initial inventory levels for the final products are given in Table 1. Disassembly yield rates for the cores A and B are 0.3 and 0.7 , respectively. In order to simplify the illustrative example, it has been assumed that lead times and failure rates for core are zero. Disassembly times and costs for each part are provided in two matrices, respectively, as shown in the following:

$$
\mathrm{DT}=\left[\begin{array}{lllll}
3 & 3 & 2 & 0 & 0 \\
0 & 0 & 3 & 2 & 1
\end{array}\right] \quad \mathrm{CD}=\left[\begin{array}{rrrrr}
30 & 15 & 30 & 0 & 0 \\
0 & 0 & 12 & 5 & 5
\end{array}\right]
$$

Table 1. Product Demands for the Illustrative Example

\begin{tabular}{|l|c|c|c|c|c|c|}
\hline & \multirow{5}{*}{$\begin{array}{l}\text { Beginning } \\
\text { Inventory }\end{array}$} & \multicolumn{5}{|c|}{ Periods } \\
\cline { 2 - 7 } & & $\mathbf{1}$ & $\mathbf{2}$ & $\mathbf{3}$ & $\mathbf{4}$ & $\mathbf{5}$ \\
\hline Product A & 5 & 20 & 15 & 17 & 18 & 20 \\
\hline Product B & 4 & 10 & 10 & 12 & 11 & 8 \\
\hline Product C & 0 & 5 & 3 & 6 & 7 & 5 \\
\hline
\end{tabular}

Unit purchasing costs for all new parts and cores are assumed to be the same for the purpose of simplicity and they are $\$ 10 /$ part and $\$ 1 /$ core. The ordering cost is $\$ 2, \$ 3, \$ 2, \$ 4$ and $\$ 2$ per order for five new parts, respectively, and it is $\$ 2$ and $\$ 3$ for cores $A$ and $B$, respectively, for five periods. Disposal costs for cores $A$ and $B$ are $\$ 2 /$ core and $\$ 3 /$ core, respectively. Holding cost is $\$ 35 /$ product/period for all final products, $\$ 1 /$ part/period for new parts, $\$ 1.5 /$ part/period for disassembled parts and $\$ 3 /$ core/period for the cores.

The corresponding integer programming model for the example is solved with GAMS optimization software on a PC. The optimal total cost is $\$ 19670.5$ after 624812 iterations. Table 2 summarizes materials requirements planning solutions of the example for part 3. The procedure calculates the parts requirements with demands and inventory data, meets the constraints and determines the sources of required parts by minimizing the total cost. In this illustrative example, in total, 64 core B (8 in period 1, 29 in period 2, 18 in period 3, 9 in period 5) and one core A (in period 1) are disassembled in order to acquire and use their parts in manufacturing. 
A Mathematical Modeling Approach for Materials Requirements Planning in Remanufacturing

Table 2. Optimal Solution for the Illustrative Example (for part $j=3$ )

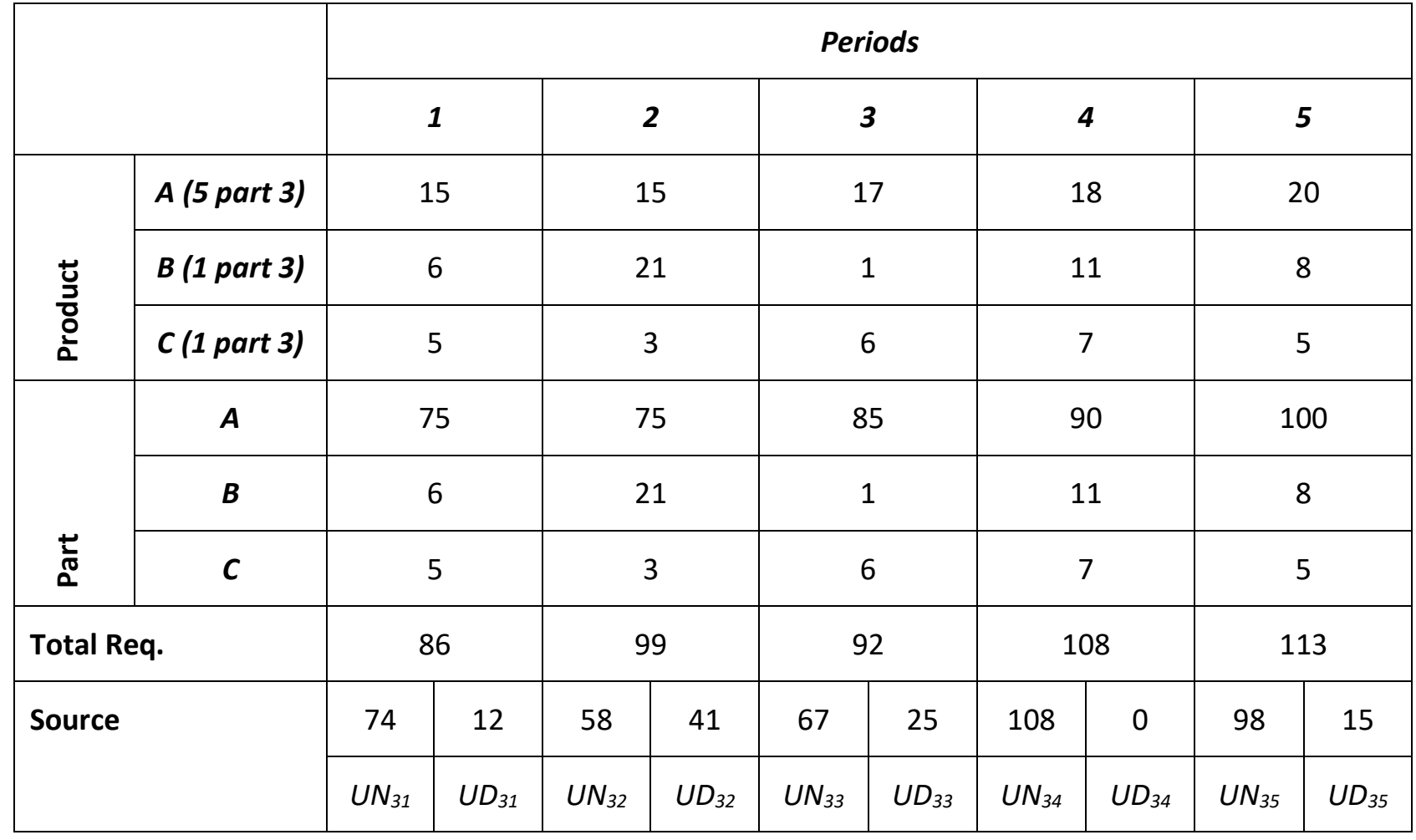

\section{Experimental Design and Findings}

In this section, the developed mathematical model is run under different remanufacturing environments. Four experimental factors are considered to generate experimental runs as shown in Table 3.

Table 3. Experimental Design Factors and Levels

\begin{tabular}{|l|l|c|c|c|}
\hline \multirow{2}{*}{ Factors } & \multirow{2}{*}{ Description } & \multicolumn{3}{|c|}{ Levels } \\
\cline { 3 - 5 } & The ratio of disassembly cost to purchasing cost & $\mathbf{1}$ & $\mathbf{2}$ & $\mathbf{3}$ \\
\hline A & Core lead time & 0.60 & 0.80 & 1 \\
\hline B & New parts lead time & 0 & 1 & 2 \\
\hline C & Disassembly yield rate & 0 & 1 & 2 \\
\hline D & & 0.3 & 0.7 & 1 \\
\hline
\end{tabular}

The remanufacturing system has 3 products, 2 cores and 5 parts with a planning horizon of 8 periods. A full factorial design with 81 design points is used to generate factor combinations. All runs are performed on an Intel Pentium 1.60Ghz., 504 MB RAM. Table 4 shows ANOVA table to determine the influential factor on the total cost. Based on the results, on the one hand, the ratio of disassembly cost to purchasing cost (A), core lead time (B) and disassembly yield rate (D) emerge as significant factors ( $p$-value $<0.05$ ). On the other hand, lead time for purchasing new part $(C)$ is shown to have a slight influence on the total cost. Some twofactor interactions, that is, $A * D, B^{*} C$ and $C * D$, are also statistically significant. 
Table 4. ANOVA Table for the Total Cost

Dependent Variable: tc
\begin{tabular}{|l|c|r|r|r|r|}
\hline Source & $\begin{array}{c}\text { Sum of } \\
\text { Squares }\end{array}$ & df & Mean Square & \multicolumn{1}{c|}{ F } & \multicolumn{1}{c|}{ Sig. } \\
\hline Model & $8.998 \mathrm{E}+010^{\mathrm{a}}$ & 33 & 2726545468 & 116,666 &, 000 \\
$\mathrm{~A}$ & 301110452 & 2 & 150555225.8 & 6,442 &, 003 \\
$\mathrm{~B}$ & 921001374 & 2 & 460500686.8 & 19,704 &, 000 \\
C & 139622602 & 2 & 69811300.94 & 2,987 &, 060 \\
D & 162257286 & 2 & 81128643.15 & 3,471 &, 039 \\
A B & 131124188 & 4 & 32781047.00 & 1,403 &, 248 \\
A ${ }^{*}$ C & 77481855.4 & 4 & 19370463.85 &, 829 &, 514 \\
A D & 262743762 & 4 & 65685940.57 & 2,811 &, 036 \\
B * C & 353568555 & 4 & 88392138.83 & 3,782 &, 010 \\
B *D & 205684077 & 4 & 51421019.18 & 2,200 &, 083 \\
C *D & 357177931 & 4 & 89294482.75 & 3,821 &, 009 \\
Error & 1098417943 & 47 & 23370594.54 & & \\
Total & $9.107 \mathrm{E}+010$ & 80 & & & \\
\hline
\end{tabular}

a. $\mathrm{R}$ Squared $=, 988$ (Adjusted R Squared $=, 979$ )

Figure 5 indicates that when disassembly cost becomes as high as purchasing cost of a new part, the total cost increases as well due to a decrease in the use of disassembly as it becomes less advantageous in comparison with purchasing new parts. Factor B is related to core lead time. As shown in Figure 6, while the lead time is longer, total cost is decreasing. The difference between the levels is statistically significant.

Figure 5. Factor Effect of the Ratio of Disassembly Cost to Purchasing Cost

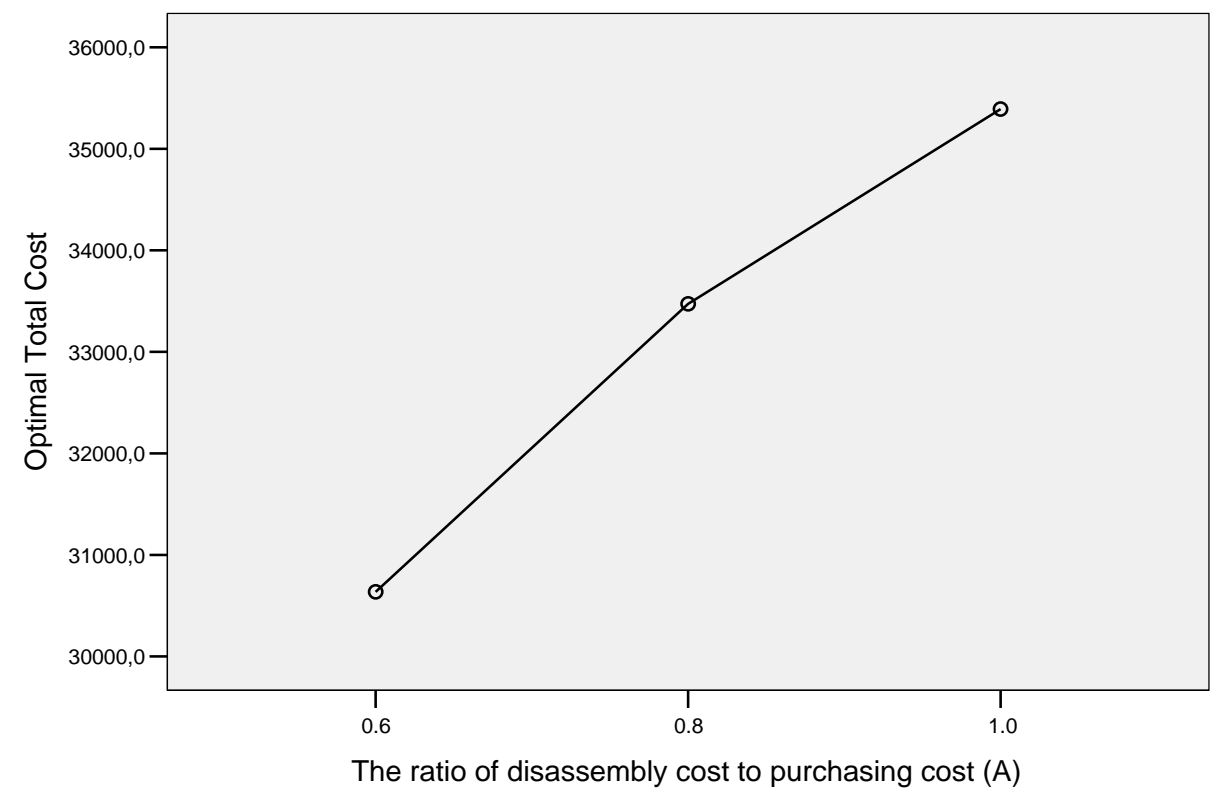


Figure 6. Factor Effect of Core Lead Time

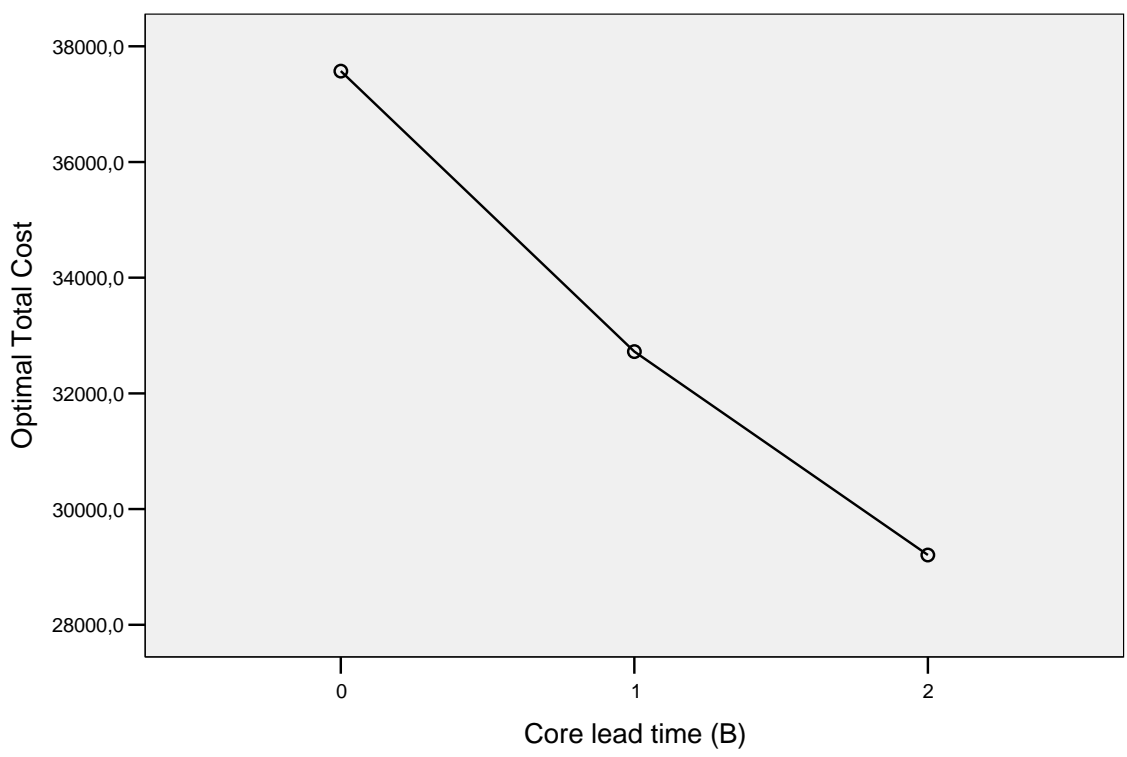

Figure 7 shows that an increase in the disassembly yield rate has a positive effect on the total cost until it reaches a $70 \%$ yield rate. At a $70 \%$ yield rate, the system takes advantage of less costly disassembled parts and, relatedly, disassembly process becomes more efficient. However, the total cost almost remains the same at a $100 \%$ yield rate. This may be due to the fact that an excess of disassembled parts will increase inventory holding costs if we disassemble the same number of cores at a $70 \%$ yield rate.

Therefore, the fewer number of cores should be disassembled to gain the same cost advantage at a $100 \%$ yield rate.

Figure 7. Factor Effect of Disassembly Yield Rate

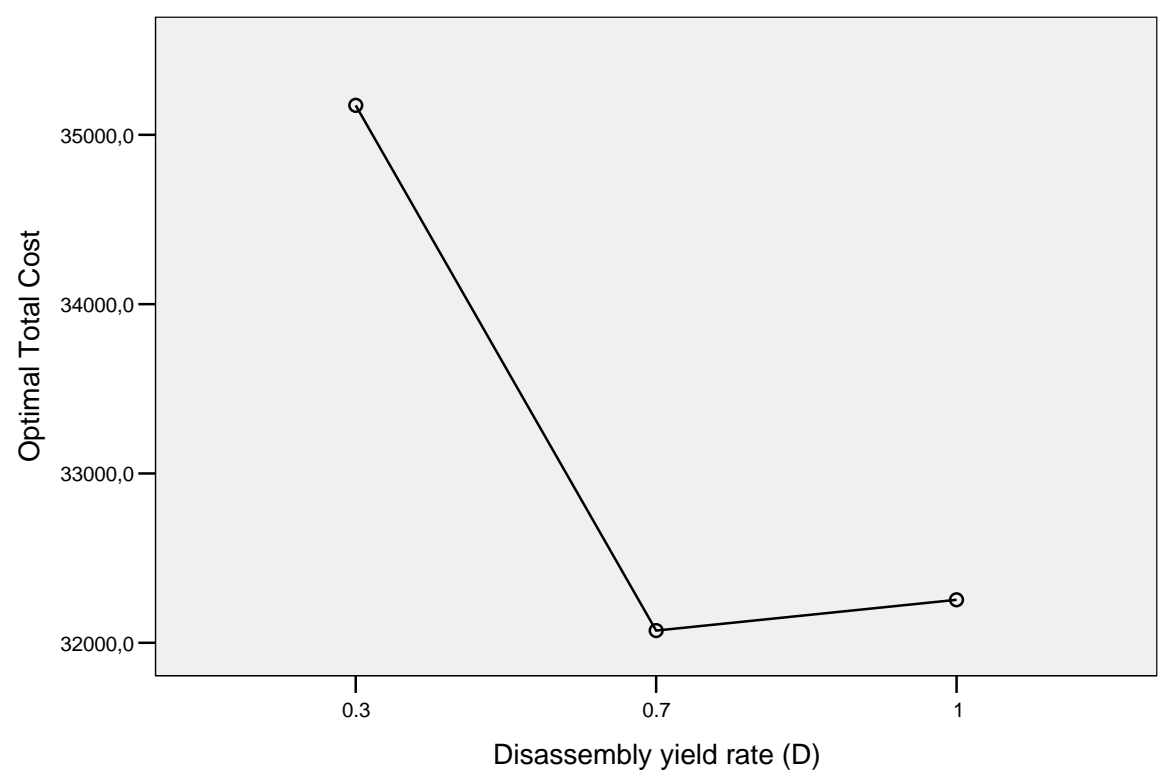

\section{Conclusions and Future Research}

Remanufacturing has been a growing practice in manufacturing due to an increasing need for environmental-friendly production strategies and better use of resources. Remanufacturing brings new challenges in production planning and logistics in addition to its benefits. Traditional materials requirements planning fails to provide an answer to every question that arises in remanufacturing. Hence, this study has 
formulated an integer mathematical programming model for multi-product, multi-period MRP decisions in a remanufacturing system with both core disassembly and procurement of new parts to assemble final products. The developed model minimizes the total manufacturing cost which includes disassembly, purchasing, disposal, holding and ordering costs. The model considers core quality, purchasing lead times, disassembly bill of materials, disassembly capacity and disassembly times of each part in core. While other studies in the literature mainly focus on the question of how much core should be disassembled, this study considers both core disassembly and new part purchasing decisions in a single model. Furthermore, other constraints (e.g. capacity or available core quantity) are considered for the environment. Unlike the existing literature which largely examine single-product and single-period problems, the present study has solved a multi-product and multi-period problem.

Extensive numerical studies on the model show that the yield rate, ratio of disassembly cost to purchase cost and core lead time statistically have a significant effect on the optimum total remanufacturing cost. This study takes into consideration the commonality across the products, which makes the scheduling of disassembly harder since it creates dependencies between the components of the product structure. The optimization problem tackled here has a non-polynomial computational complexity. Our optimization model is an integer programming model since all quantities for cores and parts must be integer. In such cases when the variables are integer, the model needs to run for a very long period in order to reach the optimum result. Taleb and Gupta (1997) focus in their study solely on the disassembly process rather than the whole remanufacturing problem. The complexity of their developed heuristic algorithm is $O\left(2^{n}\right)$ for $0-1$ integer programming while $n$ is the number of parts. Additionally, the complexity will be $O\left(2^{n^{*} h}\right)$ while the model is solved for $h$ periods. Langella (2007) indicates that complexity will increase exponentially with the number of cores, intermediate items, parts and planning periods. Our model can solve mid-size problems within a reasonable amount of CPU time. However, heuristic approaches need to be developed to obtain "good" results in solving larger problems. Further study can use simulation in order to analyze uncertainties in the yield rates, lead times, demand and core availabilities. Additionally, instead of a fixed-period horizon, a rolling horizon framework can be utilized in the scheduling of remanufacturing.

\section{References}

Barba-Gutierrez, Y., Adenso-Diaz, B., \& Gupta, S.M. (2008). Lot sizing in reverse MRP for scheduling disassembly. International Journal of Production Economics, 111, 741-751.

Brito M.P., \& Dekker, R. (2002). Reverse logistics - a framework. Econometric Institute Report El 2002-38, Erasmus University, Rotterdam.

Carter, C., \& Ellram, L. (1998). Reverse logistics: A review of the literature and framework for future investigation. Journal of Business Logistics, 19(1), 85-102.

Dowlatshahi, S. (2000). Developing a theory of reverse logistics. Interfaces, 30(3), 143-155.

Ferrer, G., \& Ayres, R.U. (2000). The impact of remanufacturing in the economy. Ecological Economics, 32 (3), 413-429.

Ferrer, G., \& Whybark, D.C. (2001). Material planning for a remanufacturing facility, Production and Inventory Management Society, 10(2), 112-124.

Fleischemann, M., Bloemhof-Ruward, M., Dekker, R., Laan, E., Nunen, A.E.E., \& van Wassenhove, L.N. (1997). Quantitative models for reverse logistics: a review. European Journal of Operational Research, 103, 1-17.

Grubbstrom, R.W., \& Tang, O. (2006). Optimal production opportunities in a remanufacturing system. International Journal of Production Research, (44) 18-19, 3953-3966.

Guide, V.D.R. (1999). Production planning and control practices for remanufacturing. Research Paper Series, APICS.

Guide, V.D.R. (2000). Production planning and control for remanufacturing: industry practice and research needs. Journal of Operations Management, 18, 467-483.

Guide, V.D.R., \& Jayaraman, V. (2000). Product acquisition management: current industry practice and a proposed framework. International Journal of Production Research, (38) 16, 3779-3800.

Guide, V.D.R., Jayaraman, V., \& Srivastava, R. (1999). Production planning and control for remanufacturing: a state-ofthe-art survey. Robotics and Computer Integrated Manufacturing, 15, 221-230. 
Guide, V.D.R., Jayaraman, V., Srivastava, R., \& Benton, W.C. (2000). Supply chain management for recoverable manufacturing systems. Interfaces, 30, May-June, 125-142.

Guide, V.D.R., \& Spencer, M.S. (1997). Rough-cut capacity planning for remanufacturing firms. Production Planning and Control, 8 (3), 237-244.

Guide, V.D.R., Srivastava R., \& Spencer, M.S. (1997). An evaluation of capacity planning techniques in a remanufacturing environment. International Journal of Production Research, 35 (1), 67-82.

Gungor, A., \& Gupta, S.M. (1999). Issues in environmentally conscious manufacturing and product recovery: a survey. Computers and Industrial Engineering, 36, 911-853.

Gupta, S.M., \& Talep, K.N., 1994. Scheduling disassembly. International Journal of Production Research, (32) 8, $1857-$ 1866.

ljomah, W.L., Mcmahon, C.A., Hammond, G.P., \& Newman, S.T. (2007). Development of robust design-forremanufacturing guidelines to further the aims of sustainable development. International Journal of Production Research, (45) 18-19, 4513-4536.

Inderfurth, K. (2004). Optimal policies in hybrid manufacturing /remanufacturing systems with product substitution. International Journal of Production Economics, 90, 325-343.

Inderfurth, K., \& Langella, I.M. (2006). Heuristics for solving disassemble-to-order problems with stochastic yields. $O R$ Spectrum, 28, 73-99.

Kim, K., Song, I., Kim, J., \& Jeong, B. (2006). Supply planning model for remanufacturing system in reverse logistics environment. Computers \& Industrial Engineering, 51, 279-287.

Langella, I.M. (2007). Heuristics for demand driven disassembly planning. Computers and Operations Research, (34) 2 , 552-577.

Lee, D.H., Kang, J.G., \& Xirouchakis, P. (2001). Disassembly planning and scheduling: review and further research. Proc. Instn. Mech. Engrs, 215 (B), 695-709.

Li, J., Gonzalz, M., \& Zhu, Y. (2009). A hybrid simulation optimization method for production planning of dedicated remanufacturing. International Journal of Production Economics, 117, 286-301.

Mukhopadhyay, S.K., \& Ma, H. (2009). Joint procurement and production decisions in remanufacturing under quality and demand uncertainty. International Journal of Production Economics, 120 (1), 5-17.

Nakashima, K., Arimitsu, H., Nose, T., \& Kuriyama, S. (2002). Analysis of a product recovery system. International Journal of Production Research, 40(15), 3849-3856.

Nenes, G., \& Nikolaidis, Y. (2012). A multi-period model for managing used product returns. International Journal of Production Research, 50(5), 1360-1376.

Rogers, D.S., \& Tibben-Lembke, R. (2001). An examination of reverse logistics practices. Journal of Business Logistics, 22 (2), 129-147.

Rubio, S., \& Corominas, A. (2008). Optimal manufacturing-remanufacturing policies in a lean production environment. Computers \& Industrial Engineering, 55, 234-242.

Stock, J.R. (2001). Reverse logistics in the supply chain. Global Purchasing \& Supply Chain Strategies, October, 44-48.

Taha, H.A. (1975). Integer programming. Theory, applications and computations. Academic Press Inc., NY.

Taleb, K.N., \& Gupta, S.M. (1997). Disassembly of multiple product structures. Computers Industrial Engineering, (32) 4, 949-961.

Taleb, K.N., Gupta, S.M., \& Brennan, L. (1997). Disassembly of complex product structures with parts and materials commonality. Production Planning and Control, (8) 3, 255-269.

Tang, O., Grubbstrom R.W., \& Zanoni, S. (2007). Planned lead time determination in a make-to-order remanufacturing system. International Journal of Production Economics, 108, 426-435.

Thierry, M., Salomon, M., Nunen, J., \& Wassenhove, L. (1995). Strategic issues in product recovery management. California Management Review, (37) 2, Winter, 114-135.

van Nunen, J.A.E.E., \& Zuidwijk, R.A. (2004). E-enabled closed-loop supply chains. California Management Review, 46 (2), 40-54.

Veerakamolmal P., \& Gupta S.M. (2000). Optimising the supply chain in reverse logistics. Environmentally Conscious Manufacturing Conference, Boston, Massachusetts, November 6-8, 2000. 